The Design, Testing and Implementation of Virginia's NOx Allowance Auction*

\author{
David Porter \\ Stephen Rassenti \\ Interdisciplinary Center for Economic Science, George Mason University \\ William Shobe \\ University of Virginia \\ Vernon Smith \\ Interdisciplinary Center for Economic Science, George Mason University \\ Abel Winn \\ Market-Based Management Center, Wichita State University
}

- We would like to thank Beth Major in Virginia's Department of Environmental Quality whose efforts were instrumental in ensuring that the auction was implemented. 


\section{The Design, Testing and Implementation of Virginia's NOx Allowance Auction}

\section{Introduction}

Among economists, at least, the use of tradable emission allowances under an aggregate emission cap is generally considered a mature policy technology. It has become the default policy option in controlling a variety of large scale air emissions, and is being increasingly considered for replacing inefficient source-specific regulation of water pollutants (Tietenberg, 2002). The same policy technology is also being used in fisheries regulation and elsewhere (National Academy of Sciences, 1999). In a competitive emissions market with low transaction costs, the initial allocation of rights will not affect the final use of the allowances. However, how the rights are allocated can have significant economic consequences through its effect on entry and exit decisions and on marginal tax rates (Goulder et al., 1999).

This paper concerns one of the first known cases where emission allowances were auctioned with the explicit intention of maximizing government revenues. On June $30^{\text {th }}$, 2004, the Commonwealth of Virginia's Department of Environmental Quality (DEQ) sold 3,710 allowances for emission of nitrogen oxides (NOx) in fiscal years 2004 and 2005 using a sequential English clock auction. The auction raised over $\$ 10.5$ million; $19 \%$ above its target revenue of $\$ 8.8$ million. Before settling on an auction format, Virginia engaged the services of experimental economists to assist in the auction design process. This paper examines the process by which the auction was designed, tested, and implemented. 
In March of 2004, the DEQ contracted with the Interdisciplinary Center for Economic Science (ICES) at George Mason University to assist in designing an auction to sell 1,855, or approximately 8\%, of its NOx allowances for each of the years 2004 and 2005 . The DEQ's main goal for the auction was that it maximize revenue generated for the state. In addition, as a political consideration it was essential that the DEQ avoid negative political consequences from the auction. To this end, DEQ officials indicated that transparency of the auction mechanism was critical.

The law that enabled the auction of the allowances required that all allowances be sold by June $30^{\text {th }}, 2004$. The limited timeframe to employ such an auction required a mechanism that could be easily and quickly implemented, and that would execute all sales in a short period of time. The process for procuring a vendor and deploying the auction was likely to take no less than one month, so the DEQ insisted that final recommendations for an auction mechanism be presented by May $31^{\text {st }}$; leaving roughly eight weeks for the design, testing and analysis of alternative auctions.

In general, there are two potential pricing formats available to the auction designer: discriminatory (or "pay-as-bid") and uniform price rules. Auctions that use discriminatory pricing pose an ex-post problem to participants, particularly those who are bidding agents for firms. Specifically, nearly all participants who are included in the final allocation realize that they could have bid less and still obtained the same set of units. Furthermore, since discriminatory pricing encourages strategic bidding below 
value, there is often a set of bidders who could have made it into the final allocation by submitting a bid that more truthfully revealed their willingness to pay for the good, but failed to do so in their pursuit of extra profits. Thus, discriminatory auctions pose a sort of catch-22 to bidders: a bidder who wins has paid too much; a bidder who loses has bid too little.

Auctions that use a uniform pricing rule avoid this problem: all bidders pay one price, so no winning bidding agent appears to have secured a poorer contract for his principal than any other winning agent. Moreover, uniform pricing rules encourage more revelation of bidders' willingness to pay. However, uniform pricing creates a new problem on behalf of the government seller. The bidding information that is used to determine the price is available to the public, who may be disturbed by what they perceive as excessive surplus left in the bidders' pockets. ${ }^{1}$ In the context of the Virginia NOx auction, the DEQ could potentially be second-guessed by the state legislature for not extracting "maximal" revenue from the buyers. Keeping the bidding information secret could resolve this problem, but because the auction was to be held on behalf of the state government, Virginia's Freedom of Information Act required eventual full disclosure of all bids.

Time constraints further complicated the selection of an appropriate mechanism. The two allowance vintages (2004 and 2005) were asymmetric substitutes and carried the risk

\footnotetext{
${ }^{1}$ For example, in November of 2000 just prior to the demise of the California Power Exchange (CPX), CEO George Sladoje wrote an open letter announcing that, because of public pressure, a Blue Ribbon Panel had been formed to examine the CPX's policy of running a uniform-price rather than pay-as-offered auction for electricity. Apparently, during the ongoing investigations into the upheaval in California prices, several parties had suggested that switching the CPX to use of a "pay-as-offered" auction would go a long way toward curtailing inflated and volatile wholesale electricity prices.
} 
of depreciation. ${ }^{2}$ These characteristics meant that the revenue maximizing allocation would likely require the use of flexible combinatorial bids and linear optimization techniques. However, any such auction would be unfamiliar to potential participants and could require extensive training sessions for which there was little or no time given the proximity of the deadline for executing the auction. Complicated bidding and allocation rules could also deter potential buyers from participating, which would reduce the auction's ability to generate revenue. DEQ initially selected the combinatorial clock design, but the complexity of implementation proved prohibitive in the available timeframe, and ultimately the sequential clock was implemented instead.

Through laboratory experiments, we estimate that, under elastic demand conditions, a combinatorial pay-as-bid auction would have allowed the state to capture roughly $65.2 \%$ of the available surplus, while using a sequential clock auction or combinatorial clock auction would increase the state's share to $84.9 \%$ or $94.2 \%$ respectively. ${ }^{3}$ Each of these mechanisms has an allocative efficiency of $95 \%$ or better.

\section{Background Information}

NOx emissions from large emitters in Virginia and 18 other states in the eastern U.S. are governed by a cap-and-trade system of pollution allowances. ${ }^{4}$ Total NOx emissions are capped at approximately 500,000 tons per year. Allowances are freely tradable throughout the 19-state region. There is an active private market for the trading of NOx

\footnotetext{
${ }^{2}$ These characteristics of the commodities that were to be auctioned are discussed in section II

${ }^{3}$ In more inelastic demand environments the clock auctions become relatively less advantageous for revenue generation.

${ }^{4}$ For an excellent synopsis of this and related programs see Burtraw et al. (2005).
} 
allowances. In the month of May, 2004 3,000 allowances ( $0.6 \%$ of the total allowances available) were traded in the over-the-counter market. Brokers post a current bid/ask spread for 50 tons. According to www.natsource.com on June 23, the day prior to the auction, the spread for 2004 allowances was $\$ 2,200 / \$ 2,350$ and for 2005 allowances $\$ 3,150 / \$ 3,200$.

Each state has a NOx emissions budget, and has considerable flexibility in allocating its budgeted emission allowances to sources. In Virginia, allowances specific to their year of issuance are allocated to firms for whom NOx emissions are a byproduct of production. ${ }^{5}$ Allowances are issued in one-ton face values, and are "bankable": allowances issued in year $y$ may be saved for use in year $y+1$ or later. However, emitters cannot borrow against future issuances of allowances for use in the current year. This asymmetric substitutability suggests that firms who needed the right to emit in 2005 would be willing to use allowances for 2004 instead, but the reverse does not hold. Theoretically, then, the 2004 allowances should command a premium, as the market for such allowances would bear demand for uses in both years.

However, the use of banked allowances is subject to a constraint designed to control the rate of their use in a given year. ${ }^{6}$ By law, if the number of allowances carried over region-wide from year $y$ to year $y+1$ exceeds $10 \%$ of the total regional budget for year $y+1$ (referred to in this paper as the "banking threshold"), then only a fraction of the source's banked allowances may be used to cover the emission of one ton of NOx in year

\footnotetext{
${ }^{5}$ Virginia Administrative Code, 2004.
} 
$y+1$; the remaining banked allowances may only be used for $50 \%$ of their nominal value, or half of a ton. The proportion of the banked allowances that may be used to cover a ton of NOx is determined by the ratio of $10 \%$ of the regional budget divided by the regional total of banked allowances. If, for instance, a firm banked 99 tons of emission worth of vintage 2004 allowances for use in 2005, and regional banking amounted to $15 \%$ of the 2005 budget, only two thirds (10\%/15\%) of a firm's banked allowances would retain their face value of one ton of NOx emissions each. The remaining one third (33 out of 99) of the banked allowances could only be used to cover one half of a ton each of NOx emissions, leaving the firm with a total coverage of 82.5 tons.

This feature complicated the substitutability of 2004 allowances for 2005 allowances, as the likelihood that some 2004 allowances would lose half their face value would lead bidders to demand them at an appropriate discount. In early March, local NOx exchanges ${ }^{7}$ were trading 2004 allowances for around $\$ 2,000$ and 2005 allowances for $\$ 3,500$, indicating that the banking threshold was very much believed to be a binding constraint.

In Virginia, most emission allowances are given to firms in recognition of their historical rights to emits established by past fossil fuel inputs. Approximately $8 \%$ of 2004 and 2005 allowances were set aside for allocation among new sources of NOx emissions in

\footnotetext{
${ }^{6}$ Virginia Administrative Code, 2004.

${ }^{7}$ Data on prices and trading volume may be found at www.natsource.com and www.evomarkets.com.
} 
each year. ${ }^{8}$ The original intent of the legislature was to dispense the set aside allowances at no charge upon request from new firms. ${ }^{9}$ However, because the state was facing budget difficulties (as was common among many states at the time), the legislature decided that these set aside allowances should be auctioned rather than freely granted to new sources. ${ }^{10}$

\section{Auction Design}

The conventional wisdom in the design of auctions is that the details matter (Klemperer, 2002). Moreover, the price discovery process requires that substitute goods be offered simultaneously and that the auction is iterative so that prices move in response to excess demand (Milgrom 2000). However, as one provides for an open iterative auction, the ability of the bidders to tacitly collude is increased (Klemperer, 1999). These issues suggest that no matter what designs are selected, it is important to test their properties in controlled settings (Ledyard, 1993; and Smith, 1994). We begin by defining the goods being auctioned.

\section{Allowance Characteristics}

Recall that allowances are bankable: the 2004 allowance is a substitute for 2005

allowance, but the converse is not true. However, there is chance that if too many 2004 allowances are banked region-wide, they will be discounted in any future year that the banking threshold is exceeded. A standard price/quantity (PQ) auction would have each participant bid separately on each allowance type, where $\mathrm{P}$ is the price per unit of the bid

\footnotetext{
${ }^{8}$ Virginia Administrative Code, 2004.

${ }^{9}$ See $\S 10.1-1322.3$ Code of Virginia.
} 
and $\mathrm{Q}$ is the maximum number of allowances that the bidder would be willing to accept at or below the price P. Participants submitting such bids would be unable to indicate to the auctioneer whether they were willing to accept 2004 allowances in place of 2005 allowances, and if so, the exchange rate at which they would be willing to do so. This would force bidders to choose between bidding too conservatively or exposing themselves to financial loss. It would also deny the auctioneer flexibility in selecting an allocation to maximize revenue and efficiency.

\section{Alternative Auction Mechanisms}

The auction mechanisms we tested can be categorized into two generic formats: sealed bid without iteration and iterative English clock. The sealed-bid auction for allowances is an extension of the familiar first price auction that also allows bids for alternative vintages (2004 and 2005) to be linked. The iterative English clock is tested with simultaneous linked clocks and also with sequential auctions.

\subsection{Sealed Bid Auction}

The simplest and most transparent of all auction mechanisms is the simple sealed bid first price auction, in which participants submit bids by a given deadline and units are allocated to the high bidders on a pay-as-bid basis. In our tests this sealed bid auction framework was augmented by replacing the standard PQ bids with "Any/Or” (AO) bids. These bids take the format $\left(\mathrm{p}_{4}, \mathrm{Q}_{4} \mid \mathrm{p}_{5}, \mathrm{Q}_{5}\right)$, where $\mathrm{p}_{4}$ is the price per allowance that the bidder is willing to pay for a block of up to $\mathrm{Q}_{4} 2004$ allowances, and $\mathrm{p}_{5}$ is the price per

\footnotetext{
${ }^{10}$ Subsection D of Item 383 of Chapter 899 of the 2002 Acts of Assembly, Commonwealth of Virginia.
} 
allowance that the bidder is willing to pay for a block of up to $\mathrm{Q}_{5} 2005$ allowances. ${ }^{11}$ Bids with $\mathrm{Q}_{4}, \mathrm{Q}_{5}>0$ indicate that the bidder is willing to purchase either up to $\mathrm{Q}_{4} 2004$ allowances at $\mathrm{p}_{4}$ per allowance or up to $\mathrm{Q}_{5} 2005$ allowances at $\mathrm{p}_{5}$ per allowance or any other proportionate combination. The quantities, $\mathrm{q}_{4}$ and $\mathrm{q}_{5}$, allocated as a result of this bid are then subject to the following constraints: $\mathrm{q}_{4} \leq \delta \mathrm{Q}_{4} ; \mathrm{q}_{5} \leq(1-\delta) \mathrm{Q}_{5} ; 0 \leq \delta \leq 1$. For example, a bid of the form $(100,10 \mid 90,20)$ could result in 4 allowances of 2004 vintage $(\delta=.4)$ and 12 allowances of 2005 vintage $(1-\delta=.6)$ being purchased. The AO bid increases the message space for bidders to convey their preferences to the auctioneer, and provides the auctioneer considerable flexibility in allocating allowances.

Given each bid $\mathrm{j}=1, \ldots, \mathrm{J}$ submitted by each participant $\mathrm{i}=1, \ldots, \mathrm{I}$, the maximal level of revenue to be derived from selling 1,855 allowances of each vintage can be found by solving the following mixed integer programming problem for the optimal quantities $\mathrm{q}_{4 \mathrm{ij}}$ and $\mathrm{q}_{5 \mathrm{ij}}$ and the proportions $\delta_{\mathrm{ij}}$ :

Maximize: $\sum_{i=1}^{I} \sum_{j=1}^{J}\left(p_{4 i j} \cdot q_{4 i j}+p_{5 i j} \cdot q_{5 i j}\right)$;

subject to:

$$
\begin{aligned}
& q_{4 i j} \leq \delta_{i j} Q_{4 i j} \\
& q_{5 i j} \leq\left(1-\delta_{i j}\right) Q_{5 i j} \\
& 0 \leq \delta_{i j} \leq 1 \\
& \sum_{i=1}^{I} q_{y i j} \leq 1,855
\end{aligned}
$$

\footnotetext{
${ }^{11}$ Bids in which either $\mathrm{Q}_{4}$ or $\mathrm{Q}_{5}$ is set equal to zero is a standard $\mathrm{PQ}$ bid.
} 


$$
q_{y i j} \in\{1,2,3, \ldots\}
$$

where:

$p_{y i j}=$ the per unit bid price for year $y$ allowances submitted in the $\mathrm{j}^{\text {th }}$ bid by bidder $\mathrm{i}$;

$Q_{y i j}=$ the maximum quantity of year $y$ allowances submitted in the $\mathrm{j}^{\text {th }}$ bid by bidder $\mathrm{i}$;

$q_{y i j}=$ the quantity of year $y$ allowances allocated to the $\mathrm{j}^{\text {th }}$ bid submitted by bidder $\mathrm{i}$.

Although this combinatorial sealed bid (CSB) auction relies on discriminatory pricing and thus presents the aforementioned ex post bidding dilemma to bidders, it remained an attractive option for the DEQ. The sealed bid format was familiar to all parties involved, and this auction could be executed quickly and with a minimum of preparation. ${ }^{12}$

\subsection{Clock Auctions}

An alternative to sealed bid auctions is the iterative auction, which allows the bidding process to give feedback to bidders to guide their strategy in the auction. One iterative auction which has received much academic attention is the English clock auction. This auction eliminates the right of participants to specify bids. Instead, it uses a clock to quote successive prices, and each bidder is required only to indicate his quantity demanded at the standing price. (McCabe et al., 1988/1991; also see: McCabe et al., 1990; Cramton and Kerr, 2002; Porter et al., 2003; and Banks et al., 2003 who discuss the chaotic problems created in the absence of an English clock auction).

\footnotetext{
${ }^{12}$ Moreover, the pay-as-bid format rather than a uniform price would allow the DEQ to avoid explaining to legislators why some participants should receive allowances at prices well below their expressed willingness to pay.
} 
Formally, the English clock auction (ECA) is composed of an unspecified number of rounds, $r$. In each round, the price $p_{r}$ is posted on an electronic "clock." In response to the clock price, each bidder $i \in\{1,2, \ldots, I\}$ indicates the quantity for that round $q_{\text {ir }}$ that he is willing to purchase. With a total supply of $Q_{s}$, if $\sum_{i=1}^{I} q_{i r}>Q_{s}$, the clock price increases by a predetermined increment, $\varepsilon$, to $p_{r+1}=p_{r}+\varepsilon$ and bidders submit a new set of $q_{i, r+1}$ at the updated price subject to the constraint that $q_{i r} \leq q_{i, r+1}$.

If in round $k$ it is the case that $\sum_{i=1}^{I} q_{i k}=Q_{s}$, then the auction terminates and every bidder receives $q_{i k}$ units at $p_{k}$ per unit. If instead it is the case that $\sum_{i=1}^{I} q_{i k}<Q_{s}$, then every bidder with $q_{i k}>0$ receives this quantity at $p_{k}$ per unit. This leaves $Q_{s}-\sum_{i=1}^{I} q_{i k}$ units to be allocated. Among the remaining bidders for whom it was the case that $q_{i, k-1}<q_{i k}$, participants are selected at random to receive $q_{i, k-1}-q_{i k}$ units at $p_{k-1}$ per unit until these leftover units have been allocated. ${ }^{13}$

For the purposes of the NOx auction, the ECA had two advantages over the CSB. First, the uniform price rule of the ECA encourages revelation of bidders' willingness to pay, potentially resulting in a more efficient outcome. Second, it solves the ex post predicament of both the bidders and the auctioneer. As a uniform price auction, it ensures that no bidder appears to have paid too high a price, and tends to ensure that 
those left out of the allocation could not have profitably procured units. As an iterative auction, it stops revealing bidders' demand at the market clearing price, generating no information concerning how much more the buyers might have been willing to pay.

Despite these advantages, the case for an ECA mechanism was not clear-cut. Using one ECA to sell the 2004 allowances and another to sell the 2005 allowances would ignore their combinatorial nature, and might result in lower revenue and efficiency. On the other hand, a combinatorial auction design using simultaneous linked clocks for the ECA would present a more complicated bidding structure to be explained to participants, thus working against the auction's need for transparency and ready adoption by potential participants.

\subsubsection{The Sequential English Clock Auction}

A straightforward application of the ECA to the NOx auction would be sequential English clock (SEC) auctions. With an SEC, one year's allowances would be sold using the ECA mechanism described above, and the remaining vintage would be sold with a separate ECA at a time soon after. This would allocate the allowances in a straightforward manner, but it would also fall prey to the risk associated with simple PQ bidding in independent auctions.

Given the asymmetric substitutability of the two allowance vintages, the order in which the vintages were to be sold was a potentially serious matter. If the 2004 allowances

\footnotetext{
${ }^{13}$ It may be the case that one participant receives $\delta q_{i k-1}$ units, where $0<\delta<1$.
} 
were sold first, bidders who intended to emit in 2005 might hedge their bets by acquiring allowances in the first auction. This could push efficient 2004 emitters out of the 2004 allocation while depressing demand for the 2005 allowances in the subsequent auction. Backwards induction would suggest that holding the 2005 auction first would eliminate potentially inefficient speculative bidding, and could therefore improve both the efficiency and revenue collection of a NOx SEC.

\subsubsection{The Combinatorial English Clock (CEC) Auction}

The combinatorial version of the ECA takes into account the potential substitutability of the 2004 and 2005 allowances. Two clocks operate simultaneously, one for each vintage. Prices are posted for each clock. At the posted prices participants respond with quantities for 2004 and 2005. As long as the total quantity demanded of a given vintage is greater than its supply, the clock price for that vintage increases. The clocks stop when total demand is less than or equal to the supply for both 2004 and 2005 allowances. If the supply exactly equals the registered demand for each vintage, the allocations are made based on the final clock prices. However, three modifications are necessary in order to allow the CEC to handle substitutions efficiently.

The first modification requires that any participant be allowed to submit multiple bids, each of which register a particular quantity of one particular vintage that he is willing to purchase at the current clock price. The second modification requires that during the auction, as the prices on the clocks increase, a particular bid for a quantity of one vintage can be switched to a quantity of the other. However, the quantity of demand that is 
switched to a given vintage is limited by any quantity attributable to that bid for that vintage earlier in the auction. For example, if a bidder had registered a bid consisting of demand for 10 of the 2004 allowances at a previous price and wished to switch that bid to the 2005 vintage given the current prices, the quantity of 2005 allowances demanded in this switched bid could not exceed 10 units.

A single exception exists to the above rule. On the first switch only (when no previous quantity of record exists) the following special rules apply: when switching from a lower to a higher priced vintage, the quantity of the higher priced vintage is limited to the quantity currently registered at the lower price; while when switching from a higher to a lower priced vintage, the quantity of the lower priced vintage is limited by the total budget committed to the current bid. The reason for the initial switch asymmetry is to accommodate both types of buyers: those who would seek a fixed quantity though the imperfect substitutes are worth more or less to them, or those who would seek proportionately more of the lesser valued vintage in order to compensate for its reduced quality. ${ }^{14}$ For example, if the current clock prices are $\$ 1,000$ for 2004 and $\$ 1,500$ for 2005 a current bid of 20 units of 2005 allowances may be switched to 30 units of 2004 allowances if the bidder has not previously switched her bid. However, a current bid of 20 allowances of the 2004 vintage may be switched to a bid of no more than 20 allowances of the 2005 vintage.

\footnotetext{
${ }^{14}$ In our experiments this first switch rule simplified to the previous quantity in either direction because our subjects were allowed to redeem an equal number units of either ' 04 or ' 05 , but at reduced values for the inferior quality ('04) good.
} 
The third modification requires that at the end of the auction, if the quantities demanded for at least one vintage are strictly less than the total available, then a revenue maximizing optimization is run (similar to the CSB auction) with the added constraints that bids from all rounds are considered, and any bids accepted from the previous rounds are purchased at the previous prices.

\section{Experimental Design}

In this section we describe the demand parameters used in the experiment, the procedures for implementing the experiments and the treatment design of the experiments.

\section{Demand Configuration}

The demand conditions for 2004 and 2005 NOx allowances that were to be sold in the State of Virginia DEQ auction were not precisely known. Demand for a significant tonnage of emission rights could be similar across vintages or differ significantly. ${ }^{15}$ Because of this uncertainty, it was important that the potential auction mechanisms be tested in a variety of demand environments. If one mechanism proved to be superior across environments, from a revenue/efficiency standpoint, a clear recommendation could be provided. If the mechanisms' performances were environment-specific, the DEQ would have to use the best available information on the real-world environment to inform their decision.

\footnotetext{
${ }^{15}$ Available data from brokerage firms was not sufficient to eliminate this uncertainty. The volume of a given contract executed by those firms did not exceed a few tons. The state's auction, on the other hand, could theoretically allocate nearly two thousand tons of a given vintage to a single bidder.
} 
Because we were comparing a first-price mechanism with uniform price mechanisms, elasticity of demand was an important consideration. The first-price rule has the revenue reducing tendency to suppress demand revelation, but the revenue enhancing feature of allowing the auctioneer to reap the full benefit of high bids. The uniform price rule encourages full demand revelation, but awards units to the high bidders at a discount. In general, the elasticity of the demand function determines which of these opposing forces will dominate, and therefore determines the revenue-maximizing auction mechanism. In particular, inelastic demands have larger revenue gains when individuals pay as bid relative to a uniform price rule. However, when demands are elastic there is more room for revenue losses from systematic bid shading with the pay-as-bid incentive versus the uniform price rule.

The magnitude of differences in the competitive equilibrium (CE) price ${ }^{16}$ between allowance vintages also had the potential to affect the performance of a given mechanism. If the CE price was almost the same across vintages, there may have been no need to allocate 2004 allowances to participants seeking 2005 allowances. In such a case, sequential auctions could be just as effective at efficiently allocating allowances and maximizing revenue as simultaneous auctions. However, if the CE price for 2004 allowances were significantly lower than their 2005 counterparts, there would be those willing to purchase and bank 2004 allowances for later use even though they faced a probability of devaluation by the EPA. Similarly, speculators would always be willing to

\footnotetext{
${ }^{16}$ The competitive equilibrium price is the price at which, if all units were sold at a uniform price, the quantity supplied would exactly equal the quantity demanded, and only the participants with the highest values for the good would be included in the allocation. Here, by CE price for a given allowance vintage
} 
reinvest their budget in whichever year's allowances seemed most undervalued. In this case, carefully measured substitutions reflected by strategic bidding would likely become necessary, and the combinatorial auction designs should dominate.

In order to determine how different auction mechanisms fare under the demand conditions described above, each experimental session consisted of testing a single auction mechanism with at least three repetitions under each of the four value environments shown in Table 1. Subjects, unbeknownst to themselves, faced the value environments in rotation, so that every four auctions comprised a cycle. Values during each cycle were disguised from the previous cycle by shifting and rotating demand schedules so that subjects could not easily develop accurate forecasts concerning competitive prices on the basis of their assigned redemption values. In each session, then, subjects went through at least three complete value environment cycles.

\section{Table 1: Value Environments}

\begin{tabular}{lcc}
\hline & Elastic Demand & Inelastic Demand \\
\hline $\begin{array}{l}\text { Same CE Price } \\
\text { for both vintages }\end{array}$ & 4 & 4 \\
Different CE Prices & 4 & \\
for both vintages & & 4 \\
\hline
\end{tabular}

we mean the CE price if only units of that vintage were up for auction, or if they were each auctioned separately. 
In addition, for the CSB one feature of interest was the minimum accepted bid. Auction theory predicts that subjects' bids will be a function of their value and the number of competing bidders (Vickrey, 1961). Nevertheless minimum accepted bids are a common safeguard against collusive activity among bidders. In most auctions we set the minimum accepted bids below the lowest assigned value, so that it was not a binding constraint. However, we also ran a number of auctions in which the minimum accepted bid was arbitrarily increased to make it a binding constraint. The effects of this high minimum bid in the laboratory would provide guidance to the DEQ as to whether the minimum accepted bid in the auction could be increased to improve revenue performance.

\section{Experimental Procedures}

Experiment sessions were conducted using ten to twelve volunteer human subjects selected at random from the George Mason University graduate and undergraduate population. Subjects were given oral instructions explaining the bidding and allocation processes of the mechanism under observation. No reference to NOx, emissions, pollution, or any other situation specific element was made in the instructions, to prevent subjects' behavior from being motivated by influences other than their potential payoffs.

All subjects' decisions were made through their private computer terminals, and communication between subjects was prohibited so as to prevent collusive behavior. Subjects received a small $(\$ 10)$ payment for attending the session, and the remainder of their earnings was based on their decisions during the experiment. Each experimental session lasted approximately 2 hours and the average earnings of a subject were $\$ 47.30$. 
Prior to each auction, each subject $i$ was assigned $\mathrm{j}$ redemption values for one or both abstract goods representing 2004 and 2005 pollution allowances (denoted $v_{i j, 04}$ and $v_{i j, 05}$ respectively). Participants were motivated to buy units of the goods in the test auctions by being told at what precise cash value they could redeem each unit purchased in each auction. For convenience in exposition, we will refer to the abstract goods sold to the subjects in the test auctions as 2004 and 2005 allowances. Each subject was given multiple redemption values; each value was for exactly one allowance of one vintage.

To model the imperfect substitutability of 2004 and 2005 allowances in the test auctions, some subjects were told that for a given vintage index $\mathrm{j}$, they could purchase and redeem either a 2004 allowance at a value of $v_{i j, 04}$ or a 2005 allowance at a value of $v_{i j, 05}$ each, but not both.

Specifically, eight of twelve subjects received simultaneous substitutable values for both allowance vintages, with the value for each 2004 allowance given as some discounted value of the corresponding 2005 allowance. These subjects represented bidders who wish to emit in 2005 (or later) and have differing expectations of the probability that 2004 allowances will have their nominal tonnage value reduced, or bidders who intend to resell allowances purchased (speculate) and have differing expectations on future resale values. Subjects' discounted 2004 values ranged from 50\% of the 2005 value (i.e., absolute certainty that 2004 allowances would be devalued) to $100 \%$ of the 2005 value (i.e., absolute certainty that there is future allowance equivalence). 
Four of twelve subjects received values only for 2004 allowances. These subjects represented bidders who need to meet compliance standards in 2004, and for whom 2005 allowances would be of no use. For simplicity, no subjects were modeled as bidders who wished to procure emissions allowances for use in both 2004 and 2005. In cases fewer

than twelve subjects were available, the number of subjects valuing only 2004 allowances was reduced, and each such subject remaining was given an increased number of redemption values for those allowances, so that the total demand in the auction remained the same. No sessions were run with fewer than eleven subjects.

\section{Treatment Design}

As noted above, we tested three auction mechanisms with declared reserve prices. The initial treatment design was to conduct five experimental sessions on each mechanism. A good response from our subject pool, however, allowed us to run more than five sessions.

In a given experimental session, each auction executed yielded one observation on the auction treatment being tested. Because of potential learning effects, observations from the first demand cycle (four auctions) during each session were excluded from the data analysis. Table 2 summarizes the number of sessions, subjects, and observations (after trimming the first four auctions per session) for each auction treatment. 
Table 2: Treatment Design and Summary of Data Collected

\begin{tabular}{lccc}
\hline Treatment & Sessions & Subjects & Observations \\
\hline CSB (Combinatorial Sealed Bid) & 8 & 96 & 120 \\
SEC 04-05 (Sequential Clock '04 First) & 11 & 132 & 88 \\
CEC (Combinatorial Clock) & & & \\
\hline Total & 6 & 69 & 75 \\
\hline
\end{tabular}

Thus, we collected data for three auction treatments in each of the four environment treatments previously described in Table 1 .

\section{Results}

The purpose of the experiments was to study revenues generated and allocation efficiency under various auction treatments. Because there are possible session and environment effects we use AR(1) random effects models for the statistical analysis. ${ }^{17,18}$

\section{Dependent Variables}

The dependent variable for the revenue model is revenue in a given round normalized by the maximum possible surplus in that round. For the efficiency model the dependent variable is the sum of values satisfied by the final allocation normalized by the sum of values that would be satisfied by the optimal allocation. These variables allowed us to

\footnotetext{
${ }^{17}$ Data used in our analysis and instructions for the experiments can be found at ices3.gmu.edu/VA_NoX

${ }^{18}$ Hausman tests were used to ensure that our use of random effects is justifiable. The $\chi^{2}(11)$ statistics from the tests on the revenue and efficiency models were $17.71(\mathrm{p}=0.0885)$ and $14.62(\mathrm{p}=0.2004)$, validating the use of random effects models.
} 
determine the percentage of the available surplus claimed by the auctioneer and the percentage of available social surplus realized by the auction.

\section{Independent Variables}

The primary independent variables are dummies indicating the auction mechanism used in a given observation (SEC and CEC). ${ }^{19}$ To test the hypothesis that the auctions' revenue generation varied in more complex CE environments, we also include the dummy variable DIFF, which took a value of 1 when the CE prices of the 2004 and 2005 vintages were different and 0 otherwise. DIFF was interacted with the mechanism variables to allow for differences across auction types.

As demand elasticity is an important part of a mechanism's comparative ability to raise revenue, we include a measure of it in the model. We define ValSpread to be:

$$
\frac{\left[\frac{\left(V_{\max }^{04}-V_{c e}^{04}\right)}{Q_{c e}^{04}}+\frac{\left(V_{\max }^{05}-V_{c e}^{05}\right)}{Q_{c e}^{05}}\right]}{2}
$$

where:

$V_{\max }^{j}$ is the maximum unit value for any bidder valuing vintage $j$ allowances;

$V_{c e}^{j}$ is the minimum value that would be included in the competitive equilibrium allocation for any bidder valuing vintage $j$ allowances;

$Q_{c e}^{j}$ is the number of $j$ allowances that would be allocated to all bidders in the competitive equilibrium.

\footnotetext{
${ }^{19}$ The CSB served as the baseline. Thus the constant term $(\alpha)$ represents the normalized revenue generated from a CSB.
} 
ValSpread is bounded between 0 and $\infty$, with 0 indicating perfectly elastic demand and $\infty$ indicating perfectly inelastic demand. ${ }^{20}$ It is included in the regression to measure the impact demand elasticity had on the revenue-generating performance of the CSB and is also interacted with the treatment variables. The inclusion of this variable brings with it the implication that the treatment dummies measure revenue generation in a perfectly elastic demand environment.

We statistically estimate the impact of the high minimum accepted bid rule with the dummy variable HighMin. As a binding constraint on bids the high minimum accepted bid rule sometimes resulted in a suboptimal quantity of units being awarded. The deviation from the optimal quantity allocated is captured in DevUnits.

All experiments were run with twelve subjects with the exception of three of the CEC sessions, in which the show-up rate would support only the eleven subject design. Because lower numbers of bidders tend to suppress competitive bidding, and because the eleven subject design was only used in the CEC treatment, we included the dummy variable DevSubs, which indicated sessions in which the number of subjects deviated from twelve.

Finally, four treatment-specific variables were included to account for learning effects. Each session consisted of a number of cycles through four value environments. Thus the variable Cycle was included which simply indicated which cycle in the session an 
observation took place in. Cycle was also interacted with the three treatment dummies to account for the possibility that learning occurred differently in the various auction mechanisms.

\section{Revenue Results}

\section{Result 1: Both English clock designs outperformed the CSB in elastic environments.}

Support: The results of the revenue model are contained in Table 3. The estimated constant is $0.6540(p<0.001)$, indicating that the CSB would generate $65.4 \%$ of the maximum revenue in a perfectly inelastic demand environment. The coefficients on $C E C$ and SEC are both positive and significant ( $p<0.001$ in each case), and suggest that the two mechanisms would generate $94.5 \%$ and $89.7 \%$ respectively of the maximum revenue given perfectly inelastic demand. The larger coefficient estimate for $C E C$ demonstrates that the combinatorial design does indeed result in higher revenue.

\section{Result 2: Inelastic demand reduced revenue across all mechanisms, but had a stronger effect on the clock auctions than the CSB.}

Support: The estimated coefficients on the VALSPREAD, CEC*VALSPREAD and SEC*VALSPREAD variables are all negative and significant $(p<0.01$ in each case). The VALSPREAD coefficient is -0.0035 , which is quite small relative to the CEC*VALSPREAD and SEC*VALSPREAD coefficients of -0.0366 and -0.0313 . This result, combined with Result 1, confirms our hypothesis that the English clock designs

\footnotetext{
${ }^{20}$ Observed values of VALSPREAD ranged between 2.22 and 12.22
} 
would generate more revenue than the CSB in elastic demand environments but less in inelastic environments.

\section{Result 3: Differences in CE prices between allowance vintages cause the CEC to significantly outperform the SEC.}

Support: Of the two variables interacting DIFF with an auction treatment, only $C E C^{*} D I F F$ displays a statistically significant coefficient. The estimate for $C E C^{*} D I F F$ is $0.0366(p<0.001)$, indicating that it tends to generate $3.7 \%$ more of the available revenue than the CSB when some 2004 allowances would be optimally allocated to emission in 2005. The insignificant coefficient for SEC*DIFF confirms our hypothesis that the CEC outperforms the SEC in complex demand environments. 
Table 3. Revenue Generation Results from Random Effects Regression

\begin{tabular}{|c|c|c|c|}
\hline Variable & Coefficient & Standard Error & P-Statistic \\
\hline$\alpha(C S B)$ & $0.6540 * *$ & 0.0220 & 0.000 \\
\hline$\beta_{1}(V A L S P R E A D)$ & $-0.0035 * *$ & 0.0014 & 0.009 \\
\hline$\beta_{2}(D I F F)$ & 0.0077 & 0.0143 & 0.590 \\
\hline$\beta_{3}(C E C)$ & $0.2913 * *$ & 0.0379 & 0.000 \\
\hline$\beta_{4}\left(C E C^{*} V A L S P R E A D\right)$ & $-0.0366^{* *}$ & 0.0025 & 0.000 \\
\hline$\beta_{5}\left(C E C^{*} D I F F\right)$ & 0.0366 & 0.0217 & 0.093 \\
\hline$\beta_{6}(S E C)$ & $0.2432 * *$ & 0.0482 & 0.000 \\
\hline$\beta_{7}\left(S E C^{*} V A L S P R E A D\right)$ & $-0.0312 * *$ & 0.0023 & 0.000 \\
\hline$\beta_{8}(S E C * D I F F)$ & -0.0294 & 0.0209 & 0.160 \\
\hline$\beta_{12}($ HighMin $)$ & $0.1779 * *$ & 0.0143 & 0.000 \\
\hline$\beta_{13}$ (DevUnits) & $-0.0134 * *$ & 0.0022 & 0.000 \\
\hline$\beta_{14}$ (DevSubs) & $-0.0578^{*}$ & 0.0289 & 0.046 \\
\hline$\beta_{15}($ Cycle $)$ & -0.0014 & 0.0052 & 0.793 \\
\hline$\beta_{16}\left(\right.$ CEC $^{*}$ Cycle $)$ & 0.0032 & 0.0107 & 0.766 \\
\hline$\beta_{17}\left(\right.$ SEC $^{*}$ Cycle $)$ & 0.0125 & 0.0158 & 0.428 \\
\hline Observations & 283 & $\mathrm{R}^{2}$ & 0.7388 \\
\hline
\end{tabular}

Result 4: High minimum bids increased revenues, but this was offset by unallocated units 
Support: The HighMin coefficient is of substantial magnitude: $0.1779(p<0.001)$.

Auctions in which a bid-constraining minimum accepted bid was imposed generated nearly $18 \%$ more of the available revenues than auctions in which the minimum accepted bid was non-constraining. However, note the DevUnits coefficient of -0.0134 ( $p=$ 0.000). This implies that if the minimum accepted bid is raised beyond the CE price, $1.3 \%$ of the available revenue is lost for each unit that is remains unallocated. In our experimental environment 13 units (about $36 \%$ of the total available) would have to remain unallocated to fully offset the revenue enhancement of the high minimum accepted bid rule.

\section{Result 5: There was no learning from cycle to cycle.}

Support: Neither Cycle nor any of its interactions with the treatment dummies have statistically significant coefficients. We therefore cannot reject the hypothesis that participants' bidding behavior remains constant for all cycles after the first.

These results show that given sufficiently elastic demand, the CEC is the revenue maximizing mechanism, but the CSB raises more revenue in inelastic demand environments. Although a significantly large block of allowances was to be offered in the auction, we suspected that the revealed demand in the DEQ's auction would be quite elastic as participants were unlikely to pay prices significantly higher than those being charged elsewhere in existing over-the-counter markets for NOx allowances. 
The experimental results also suggest that there was little if any learning curve in participating in a series of these auctions. Subjects appear to have behaved the same in earlier auctions as they did in later auctions.

\section{Efficiency Results}

\section{Result 6: The CEC allocates allowances more efficiently than the CSB or SEC.}

Support: The coefficient on CEC is positive and significant $(p<0.001)$. The estimated value of the constant is $0.9523(p<0.001)$, indicating that on average subjects in the CSB managed to achieve $95.2 \%$ of the available surplus.

The coefficient on CEC is $0.0404(p<0.001)$, demonstrating that subjects in the CEC sessions achieved $99.3 \%$ of the surplus. The coefficient on SEC is positive but insignificant. We therefore cannot reject the hypothesis that the SEC allocates resources no better or worse than the CSB.

\section{Result 7: The CSB outperforms the SEC in complex demand environments.}

Support: The coefficient for DIFF is $0.0141(p=0.001)$, indicating that the CSB's efficiency properties are enhanced when some 2004 allowances are allocated to 2005 uses. Conversely, SEC*DIFF is estimated at $-0.0198(p=0.001)$. Our model therefore predicts that an additional $3.4 \%$ of the available social surplus is realized when the CSB is used in complex demand environments versus the SEC. 
Result 8: A high minimum bid rule slightly increases efficiency, but is quickly counteracted by unallocated units.

Support: The HighMin coefficient predicts nearly $3.2 \%$ in additional social surplus when the high minimum accepted bid rule is in place $(p<0.001)$. However, DevUnits is estimated at $-0.0237(p<0.001)$, indicating that if just two units $(5.6 \%$ of available units $)$ go unallocated the net effect of the rule is damaging to efficiency. 
Table 4. Efficiency Results from Random Effects Regression

\begin{tabular}{|c|c|c|c|}
\hline Variable & Coefficient & Standard Error & P-Statistic \\
\hline$\alpha(C S B)$ & $0.9523 * *$ & 0.0058 & 0.000 \\
\hline$\beta_{1}(V A L S P R E A D)$ & -0.0001 & 0.0004 & 0.754 \\
\hline$\beta_{2}(D I F F)$ & $0.0141 * *$ & 0.0042 & 0.001 \\
\hline$\beta_{3}(C E C)$ & $0.0404 * *$ & 0.0097 & 0.000 \\
\hline$\beta_{4}\left(C E C^{*} V A L S P R E A D\right)$ & -0.0019 & 0.0008 & 0.013 \\
\hline$\beta_{5}\left(C E C^{*} D I F F\right)$ & -0.0106 & 0.0064 & 0.098 \\
\hline$\beta_{6}(S E C)$ & 0.0156 & 0.0129 & 0.224 \\
\hline$\beta_{7}\left(S E C^{*} V A L S P R E A D\right)$ & $-0.0015^{*}$ & 0.0007 & 0.045 \\
\hline$\beta_{8}\left(S E C^{*} D I F F\right)$ & $-0.0198 * *$ & 0.0062 & 0.001 \\
\hline$\beta_{12}($ HighMin $)$ & $0.0317 * *$ & 0.0043 & 0.000 \\
\hline$\beta_{13}($ DevUnits $)$ & $-0.0237 * *$ & 0.0007 & 0.000 \\
\hline$\beta_{14}($ DevSubs $)$ & -0.0103 & 0.0061 & 0.089 \\
\hline$\beta_{15}($ Cycle $)$ & -0.0009 & 0.0013 & 0.511 \\
\hline$\beta_{16}\left(C E C^{*}\right.$ Cycle $)$ & 0.0007 & 0.0028 & 0.803 \\
\hline$\beta_{17}\left(S E C^{*}\right.$ Cycle $)$ & 0.0093 & 0.0043 & 0.030 \\
\hline Observations & 283 & $\mathrm{R}^{2}$ & 0.8856 \\
\hline
\end{tabular}




\section{Result 9: Learning occurred only in the SEC treatment.}

Support: Among the interaction variables including Cycle, only SEC*Cycle is significant $(p=0.030)$. It is, however, fairly small, indicated an improvement in efficiency of less than $1 \%$ per cycle.

\section{Implementation Summary and Conclusions}

Whatever their strengths and limitations, economic experiments in support of public policy decisions are only one step in the policy design and implementation process. The Virginia NOx allowance auction had to be implemented on an extremely tight time line in order to meet a statutory deadline. This tight timeline had three important effects: first, it forced state administrators to make very quick decisions; second, it forced selection of an easily implemented auction design that would be attractive to potential participants; and third, it limited the opportunities for involvement by outside parties in the decision process.

In late April of 2004, the staff responsible for the auction received reports of experimental results demonstrating a potentially significant revenue advantage of using a combinatorial English clock auction over a combinatorial sealed bid design. The results of this research were not made public. Due to the short time line, those involved assumed that a sealed bid auction would be the only practicable option. A request for proposals (RFP) for brokerage services to implement an auction was published on May 17 for a 10day period mandated by state procurement rules. Review of bids began on May 27. The RFP had not specified an auction form and most proposals included either a sealed bid 
design or standard brokerage services or both. Astonishingly, the proposal from Amerex Energy of Houston recommended an English clock auction. ${ }^{21}$ The proposal contained assurances that the auction could, in fact, be accomplished within the short remaining time period. This proposal was selected for its potential to achieve higher revenues as indicated by the experimental results. The contract for services was signed on June 8, just 22 days before the final deadline to hold the auction.

The extremely tight deadline for holding the auction drove a number of choices about the final auction design. A web-based auction design was chosen to maximize participation and to minimize the time needed for software development. To prevent bidders from using strategies based on default, all bidders had to demonstrate credit-worthiness with a credit instrument or an escrow account with their maximum possible bid. ${ }^{22}$ A key compromise was the abandonment of the combinatorial auction design. Given the short time for training bidders, the hard choice was made to abandon combinatorial bidding in favor of two separate, sequential auctions of the 2004 and 2005 vintages. ${ }^{23}$

On June 24, the auction was held in two sessions. Vintage 2004 allowances were sold in the morning and 2005 allowances in the afternoon. Bidders included energy companies from across the 19-state region and a number of brokerage houses. In each case, the first two rounds were executed in 15 minutes each with all subsequent rounds executed in

\footnotetext{
${ }^{21}$ Amerex conducted research the issue of emission auction design on the internet. An article by Cramton and Kerr (2002) convinced them that the English clock design should be used in their proposal. [Personal conversation with Amerex staff.]

${ }^{22}$ Some potential bidders refused to participate due to this requirement.

${ }^{23}$ The brokers received signals from several important potential bidders that they might refuse to participate under this novel, not-well-understood, combinatorial bidding format.
} 
only 10 minutes each. Starting prices, at $\$ 1,900$ and $\$ 2,900$ for 2004 and 2005

respectively, were set, based on morning spot prices. In any round in which there was excess demand, the clock price ticked up by a predetermined increment in the next round: $\$ 50$ for the first 2 rounds and $\$ 25$ for any round after that.

Starting with 18 bidders, the 2004 auction went 15 rounds in 160 minutes. There were 10 winning bidders at the clearing price of $\$ 2,325$, which was $3.3 \%$ higher than a morning transaction on the spot market. Sixteen bidders entered the 2005 auction, which went 19 rounds in 200 minutes. There were 5 winning bidders at the clearing price of $\$ 3,425$, a $7 \%$ premium over the morning spot market trades. All of the winning bidders were energy firms. The $\$ 10.5$ million in net revenues were deposited to the state's general fund. The Cantor Fitzgerald market index for 2004 NOx allowances rose $4.36 \%$ on the day, and $6.14 \%$ for 2005 allowances. ${ }^{24}$ The discount ratio of the winning auction prices indicated that the estimated carry-over, c, from 2004 to 2005 would be $28 \%(2325 / 3425=$ $10 / \mathrm{c}+.5(\mathrm{c}-10) / \mathrm{c} \Rightarrow \mathrm{c}=27.95)$ of the 2005 baseline: this is much lower than the risk averse $70 \%$ forecast by the prices quoted early in March by local OTC exchanges.

Every application of an economic design problem in the field has its own unique features even though ex post it may be the case that some of the learning from past experience transfers to the new situation. The advantages of using the laboratory to test-bed a new application are that 1) it enables exploration of the parameter space where there are no empirical guidelines to identify the parameters, e. g., demand elasticity for allowances; 2)

\footnotetext{
${ }^{24}$ See www.emissionstrading.com.
} 
by comparing the revenue and efficiency of alternative auction designs it sets the stage for a more informed decision if compromises have to be made to satisfy time or other constraints on the final choice; 3) by reducing uncertainty and demonstrating feasibility—real people can actually execute the procedures — it enables all parties to feel more comfortable and confident of their ability to achieve a satisfactory outcome; 4) in this instance, it facilitated the final choice of a contractor to run the auction; 5) the cost of achieving these benefits is small-in this case, less than $1 \%$ of the resulting revenue from the auction. 


\section{References}

Banks, J., M. Olson, D. Porter, S. Rassenti and V. Smith, “Theory, Experiment and the FCC Spectrum Auctions," J. of Economic Behavior and Organization, Vol. 51, July 2003.

Burtraw, D., D. Evans, A. Krupnick, K. Palmer, and R. Toth. "Economics of Pollution trading for SO2 and NOx," Annual Review of Environment and Resources, Vol. 30, November 2005.

Cramton, P. and S. Kerr, "Tradeable Carbon Permit Auctions: How and Why to Auction Not Grandfather," Energy Policy, 30, 333-345, 2002.

Goulder, L., I. Parry, R. Williams, and D. Burtraw. "The Cost-effectiveness of Alternative Instruments for Environmental Protection in a Second-Best Setting," Journal of Public Economics, 72(3):329-60, 1999.

ICF consulting, Economic Analysis of Alternate Methods of Allocating NOx Emission Allowances, Prepared for the Acid Rain Division Office of Air and Radiation United States Environmental Protection Agency, October 1999.

Klemperer, P. “Auction Theory: A Guide to the Literature," Journal of Economic Surveys, 1999.

Klemperer, P. "What Really Matters in Auction Design," Journal of Economic Perspectives, 2002.

Ledyard, J. "The Design of Coordination Mechanisms and Organizational Computing," Journal of Organizational Computing, 3(1), pp. 121-134, 1993.

McCabe, K., S. Rassenti and V. Smith “Testing Vickrey”s and Other Simultaneous Multiple Unit Generalizations of the English Auction, "1988. Revision published in Isaac, R. M. (ed), Research in Experimental Economics, Vol. 4. JAI Press, Greenwich, CT, 1991 
McCabe, K., S. Rassenti and V. Smith,. "Auction Institutional Design: Theory and Behavior of Simultaneous Multiple-Unit Generalizations of the Dutch and English Auctions," American Economic Review, 1990 Vol. 80 (5) pp. 1276-83.

Porter,D., S. Rassenti, A. Roopnarine, and V. Smith “Combinatorial Auction Design,” Proceedings of the National Academy of Sciences 2003 100: 11153-11157.

Milgrom P. "Putting Auction Theory to Work: The Simultaneous Ascending Auction," Journal of Political Economy, 108:2 (April, 2000), 245-272.

National Academy of Sciences (NAS), Sharing the Fish: Toward a National Policy on Individual Fishing Quotas (Washington, DC: National Academy Press, 1999).

Smith, V. "Economics in the Laboratory," The Journal of Economic Perspectives, Vol. 8, No. 1 (Winter, 1994), pp. 113-131.

Tietenberg, T., "The Tradable Permits Approach to Protecting the Commons: What Have We Learned?" In National Research Council, The Drama of the Commons. Committee on the Human Dimensions of Global Change. E. Ostrom et al, eds. (Washington: National Academy Press, 2002): 197-232.

Vickrey, W., "Counterspeculation, Auctions, and Competitive Sealed Tenders," The Journal of Finance, Vol. 16, No. 1 (Mar., 1961), pp. 8-37.

Virginia. Administrative Code (VAC), "Regulations for Emissions Trading," 9 VAC 5$140,2004$. 